\title{
Disclosing Patterns in IT Project Management - A Rough Set Perspective
}

\author{
Georg Peters ${ }^{1}$ and M. Gordon Hunter ${ }^{2}$ \\ 1 Munich University of Applied Sciences \\ Department of Computer Science and Mathematics \\ 80335 Munich, Germany \\ georg. peters@hm. edu \\ 2 University of Lethbridge \\ Faculty of Management \\ Lethbridge, Alberta T1K 3M4, Canada \\ ghunter@uleth.ca
}

\begin{abstract}
Information technology has become one of the most important infrastructure components of virtually any organization. Although information technology has a crucial impact on the success of organizations it is reported that IT projects have rather high failure rates. Therefore, it is vitally important for organizations to improve the performance and success rates of IT projects. However, the reasons for failures are versatile and an ongoing very active fields of research especially in information systems and management. An established approach to evaluate IT projects is to define relevant so called critical success factors and analyze IT projects according to these criteria. This analysis is often of a qualitative nature. The objective of our paper is to enrich the analysis of critical success factors by alternative methods in particular rough set theory. We motivate the usage of rough sets to further improve the analysis of critical success factors with the goal to better manage IT projects and increase their success rate.
\end{abstract}

Keywords: Uncertainty, Soft Computing, Rough Sets, IT Project Management, Critical Success Factors.

\section{Introduction}

Although the management of IT projects has a long history of many decades it still is a challenging and risky venture to implement software in organizations no matter whether it is individual software or ERP systems. There have been countless reports on spectacular IT project failures and figures about failure rates go up as high as up to 60 percent. Therefore, very active research in information systems concentrates on the evaluation of IT projects and concepts of how to successfully manage them.

Due to the nature of these projects research in this area is often of a qualitative nature. Since, rough set theory provides very useful concepts to deal with qualitative data it can enrich the analysis of IT projects.

S. Chaudhury et al. (Eds.): PReMI 2009, LNCS 5909, pp. 591 596 2009.

(C) Springer-Verlag Berlin Heidelberg 2009 
Therefore, the objective of the paper is to evaluate the potentials of rough set theory for the analysis of critical success factors in IT projects, particularly the implementation of ERP software.

The remaining paper is organized as follows. In Section 2 we discuss main challenges and give an overview of critical success factor for IT projects. In the following section we present a rough set approach to analyze the critical success factors. The paper concludes with a summary in Section 4.

\section{Challenges in IT Project Management}

\subsection{Challenges}

Challenges and failures of IT projects have been widely discussed in the literature (e.g. 12]). Even after roughly two decades of experience in IT project management these projects are of high risk. Besides failing IT projects often exceed time and budget constraints.

\subsection{Critical Success Factors}

To address the challenges of IT projects critical success factors have been suggested and evaluated to give guidelines how to set up and run a successful IT project 3456178 . Due to the complexity of IT projects much of the research on critical success factors is of a qualitative nature rather than based on quantitative research methods.

The critical success factors as investigated by Somers and Nelson [9] have gained reasonable attention in literature. Somers and Nelson evaluated the importance of the given critical success factors by interviewing IT project managers. The critical success factors ordered in decreasing relevance are shown in Tab. 1]

We use these critical success factors in our research to disclose IT project patterns in the following Section.

Table 1. Critical Success Factors 9 ]

Top management support

Project team competence

Interdepartmental cooperation

Clear goals and objectives

Project management

Interdepartmental communication

Management of expectations

Project champion

Vendor support

Careful package selection

Data analysis and conversion
Dedicated resources

Use of steering committee

User training on software

Education on new business processes

Business Process Reengineering

Minimal customization

Architecture choices

Change management

Partnership with vendor

Use of vendors' tools

Use of consultants 


\section{Rough Set Based Analysis of Critical Success Factors}

\subsection{Preliminaries}

Rough sets were introduced by Pawlak [10/11/12 in the early eighties of the last century. The core idea of rough sets is to describe a set by two approximations, its lower and upper approximation. While the objects in the lower approximation surely belong to the set, the membership of the objects in the upper approximation is unclear - they may or may not belong to the set. Obviously, to obtain this ambiguous status, these objects have to be members of at least two different upper approximations simultaneously.

Applying this concept to the analysis of critical success factors in IT project management we define the two sets green and red which describe the project statu.1. Projects assigned to the lower approximation of the green set are considered to run well and therefore 'just' need the normal attention of the management. IT projects assigned to the lower approximation of the red set are definitely at risk so they need management action to be taken immediately.

The status of the projects in the upper approximations of the set red as well of the green set is unclear. They may run well or they may be at risk. To obtain a traffic light style project monitoring system (see Fig. 1) they are labeled with the color yellow to indicate that they require a more detailed analysis to identify their current project status. Therefore, summarized, we obtain the following traffic light style project monitoring system:

- Red: The project is at risk.

- Yellow: The project needs further investigations before a decision on its status can be made.

- Green: The project runs well.

The underlying rough set based analysis consists of the following two major steps (see Fig. 1):

1. Classifier Design - Creating the Rough Decision Table. The classifier design mainly consists of defining the rough decision table which will be used to evaluate the status of the project.

2. Classification - Deciding on the Project Status. The decision on the project status and definition of any consequent action is often within the responsibility of so called steering committees. Based on the rough decision table the steering committee can be provided with a traffic light system that classifies the IT projects.

These two steps, classifier design and classification, will be discussed in more detail in the following sections.

\footnotetext{
${ }^{1}$ Further research may lead to a refined structure of sets.

${ }^{2}$ Note, we use the terms classify and classifier in the sense that new data are assigned to the cluster obtained by a cluster analysis. Both terms are also used in supervised learning and have a different meaning there.
} 


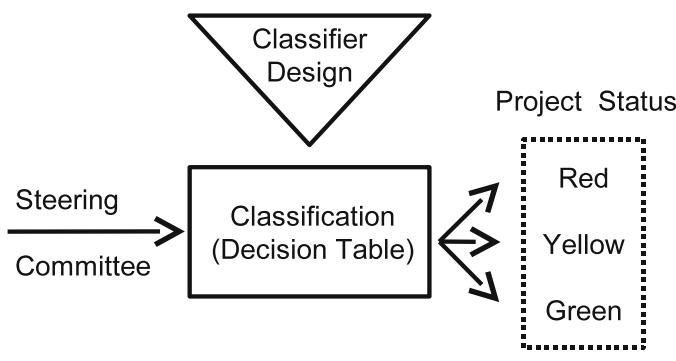

Fig. 1. Mile Stone Decision of a Steering Committee

\subsection{Classifier Design - Creating the Rough Decision Table}

For the design of the classifier, the rough decision table, we propose to interview experienced project managers or evaluate completed IT projects according to predefined critical success factors. For each IT project a record in the decision table will be created.

Due to the space limitations of the paper we use a simple sample decision table consisting of six (fictitious) interviews and a reduced set of four critical success factors as depicted in Tab. 2.

Table 2. A Sample Decision Table for IT Projects

\begin{tabular}{l||l|l|l|l||l}
$\#$ & $\begin{array}{l}\text { Top } \\
\text { Management } \\
\text { Support }\end{array}$ & $\begin{array}{l}\text { Project } \\
\text { Team } \\
\text { Competence }\end{array}$ & $\begin{array}{l}\text { User } \\
\text { Training on } \\
\text { Software }\end{array}$ & $\begin{array}{l}\text { Use of } \\
\text { Consultants }\end{array}$ & $\begin{array}{l}\text { Decision: } \\
\text { Project } \\
\text { Status }\end{array}$ \\
\hline \hline 1 & moderate & high & extensive & no & red \\
2 & low & weak & moderate & yes & red \\
3 & Strong & high & moderate & yes & green \\
4 & moderate & weak & low & no & red \\
5 & moderate & high & extensive & no & green \\
6 & moderate & high & extensive & yes & green
\end{tabular}

The records 2 and 4 are unambiguous members of the set red while the records 3 and 6 clearly belong to the set green. However, the records 1 and 5 have identical arguments but lead to different decisions. So, their memberships are equivocal. In rough set terms they belong to the upper approximations of both, the green and the red, sets 13 .

Note that the design of the decision table can easily be enriched by missing attribute values as suggested by Grzymala-Busse [14.

\subsection{Classification - Deciding on the Project Status}

Based on the rough decision table as developed in the previous section the classification of IT projects is straight forward. In an on-going project the relevant 


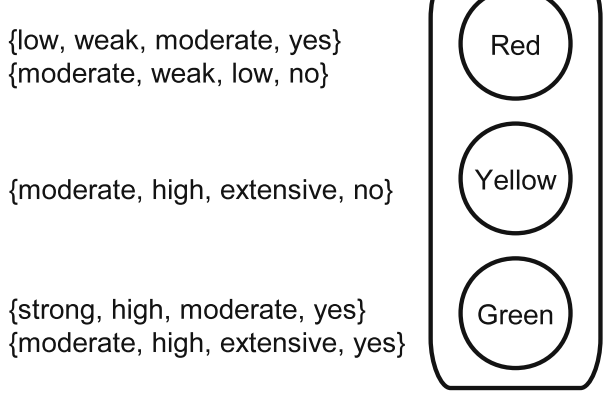

Fig. 2. Traffic Light Style IT Project Monitoring System

attribute values have to be determined and compared to the attribute values of the rough decision table. The classification rules according to the traffic light system are depicted in Fig. 2

After each classification the rough decision table has to be verified again. For example, an IT project is classified as 'green' but eventually fails. So, a new record has to be inserted into the rough decision table with the project status 'red'. Consequently the attribute values lead to contradicting project status now ('green' and 'red'). Therefore the traffic light has to be updated and must indicate 'yellow' for this set of attribute values.

In the case of a new set of attribute values the IT project has to be classified whether it is regarded as successful or not. Based on this evaluation the rough decision table has to be extended. Finally, the rough decision table has to be analyzed again to identify any changes in the upper and lower approximations.

\section{Conclusion}

In this paper we presented a potential application of rough sets for the analysis of critical success factors in IT projects, particulary ERP projects. We showed that - based on the evaluation of their critical success factors - IT projects can be group into classes.

We suggested a traffic light system indicating whether an IT project runs well, is at risk, or has an unclear status. Such a traffic light system is well accepted in management since it provides easily assessable status information within a company. While a green status project does not require more management attention, projects with a yellow status need further investigation, and red projects require immediate action.

Our future research will include an extensive case study to further evaluate and validate the proposed method and to develop a more advanced rough decision table of the critical success factors in IT projects. 


\section{References}

1. Avital, M., Vandenbosch, B.: SAP implementation at Metalica: an organizational drama in two acts. Journal of Information Technology 15, 183-194 (2000)

2. Chen, C., Law, C., Yang, S.: Managing ERP implementation failure: A project management perspective. IEEE Transactions on Engineering Management 56(1), 157-170 (2009)

3. Akkermans, H., van Helden, K.: Vicious and virtuous cycles in ERP implementation: A case study of interrelations between critical success factors. European Journal of Information Systems 11(1), 35-46 (2002)

4. Al-Mashari, M., Al-Mudimigh, A., Zairi, M.: Enterprise resource planning: A taxonomy of critical factors. European Journal of Operational Research 146(2), 352364 (2003)

5. Hsu, L.L., Lai, R.S.Q., Weng, Y.T.: Understanding the critical factors effect user satisfaction and impact of erp through innovation of diffusion theory. International Journal of Technology Management 43(1-3), 30-47 (2008)

6. Nah, F.F., Lau, J.L., Kuang, J.: Critical factors for successful implementation of enterprise systems. Business Process Management Journal 7(3), 285-296 (2001)

7. Plant, R., Willcocks, L.: Critical success factors in international ERP implementations: A case research approach. Journal of Computer Information Systems 47(3), 60-70 (2007)

8. Kappelman, L.A., McKeeman, R., Zhang, L.: Early warning signs of it project failure: The dominant dozen. Information Systems Management 23(4), 31-36 (2006)

9. Somers, T., Nelson, K.: The impact of critical success factors across the stages of enterprise resource planning implementations. In: Proceedings of the 34th Hawaii International Conference on System Sciences, Maui, Hawaii (2001); (on CD)

10. Pawlak, Z.: Rough sets. Report 431, Institute for Computer Science. Polish Academy of Sciences (1981)

11. Pawlak, Z.: Rough sets. International Journal of Computer and Information Science 11, 341-356 (1982)

12. Pawlak, Z.: Rough Sets: Theoretical Aspects of Reasoning about Data. Kluwer Academic Publishers, Dordrecht (1991)

13. Grzymala-Busse, J.: Introduction to rough set - theory and applications. In: Tutorial at KES 2004 - 8th International Conference on Knowledge Based Intelligent Information \& Engineering Systems, Wellington, New Zealand, pp. 2004-2008 (2004)

14. Grzymala-Busse, J.: Three approaches to missing attribute values: A rough set perspective. In: Lin, T., Xie, Y., Wasilewska, A., Liau, C. (eds.) Data Mining: Foundations and Practice. Studies in Computational Intelligence (SCI), vol. 118. Springer, Heidelberg (2008) 